\title{
Research on Narrative Expression Design of Industrial Heritage Landscape Under the Implicit Process
}

\author{
Hui Lin ${ }^{1,3}$, Ke Xing ${ }^{2,3}$, Xiaogang Chen ${ }^{1,3}$ \\ ${ }^{1}$ College of Urban Construction, Jiangxi Normal University, Nanchang 330022, China \\ ${ }^{2}$ College of Fine Arts, Jiangxi Normal University, Nanchang 330022, China \\ ${ }^{3}$ Geodesign Research Centre, Jiangxi Normal University, Nanchang 330022, China
}

\begin{abstract}
The industrial heritage landscape carries the special memory of the industrial civilization and the city, and has been paid more and more attention by people. The problems faced by the regeneration, utilization and protection of industrial heritage landscapes are multi-dimensional. Based on the perspective of the recessive process, this paper expounds the theory and internal relationship between the industrial heritage landscape and the narrative expression of the landscape, and proposes a design strategy for the narrative expression of the industrial heritage landscape under the recessive process. The regeneration design of industrial heritage landscape is carried out on three levels: place meaning, constructing the text of the hidden process of the landscape, and realizing the transformation of the text text narrative information. Through the implicit process that subverts and complements the development of the plot, another layer of ideographical track is constructed that is parallel to the narrative expression of the industrial heritage landscape in the past, which is based on the development of the plot. A more complex response enriches the narrative expression of the industrial heritage landscape, makes the overall character and expression of the industrial heritage landscape fuller and more intense, and strengthens the viewer's cultural experience and spiritual and cultural value identification with the local industrial heritage landscape. Solve the problems of the lack of cultural connotation and the need to activate the multi-dimensional value level faced by the industrial heritage landscape.
\end{abstract}

Keywords: Covert progression, Industrial Heritage Landscape, Narrative expression.

\section{Introduction}

"Covert progression" comes from the dual narrative process theory proposed by Chinese scholar Shen Dan, which is an innovation beyond Aristotle's narrative tradition. Since the field of narratology has been focusing on plot development from Aristotle in ancient Greece to today, and never found a narrative undercurrent hidden behind the plot development of many works, Shen Dan found and pointed out this problem, and since 2012, he has been focusing on the exploration and research of covert progression. At the same time, it puts forward the differences between covert progression and previous plot development dimensions in terms of various deep meanings, and also defines a narrative process that runs side by side with plot development from beginning to end, self-contained and independent, as "covert progression"[1]. Covert progression and plot development in the dual narrative process show different or even opposite situations, and covert progression often has a certain irony, but just because of this, covert progression is not only in the works. In the thematic sense, the characterization and aesthetic value also show a relationship with the development of the plot, which is complementary to the plot, or is opposed to the subversion, so that the reader's response is doubled or complicated. Shen Dan also pointed out that if the dual narrative dynamics formed by covert progression and plot development are ignored, it will cause a one-sided understanding or even a serious misunderstanding of the related works, and if it is translated into landscape works, it will also cause a related one-sided understanding, that is, "Dual narrative process" poses a major challenge to various related theories and methods in the past, and also opens up ideas for other research fields. At present, the industrial heritage landscape is faced with the problems of lack of cultural connotation, monotonous place spirit and other value dimensions that need to be activated. The research on the narrative expression design of industrial heritage landscape at home and abroad only stays in the explicit process, that is, the dimension of plot development. The innovation of covert progression in narratology provides a covert progression path for the narrative expression of industrial heritage landscape, and provides a new idea for effectively enriching the content of narrative expression of industrial heritage landscape and activating the value dimension at all levels.

\section{The Fundamental Concepts and Theoretical Elaboration}

\subsection{Covert Progression}

"Covert progression" is an implicit narrative movement from start to finish in a work, built primarily on non-figurative storytelling and storytelling techniques. Covert progression is hidden behind the development of the plot in the explicit process. It shows a complementary and subversive relationship with the explicit process in terms of ethical value or thematic significance. It usually has high aesthetic value and often has a changeable irony.

The components of covert progression are textual elements that appear to deviate from the plot path and point in a different direction than the plot development path, but it deserves attention because this implicit process has a direct subversive relationship with the explicit process, and if only the explicit process is seen Sexual process, not only a serious misunderstanding of the author's rhetorical purpose, but also a serious misunderstanding of the thematic meaning of the work. In addition, on the level of irony, the covert progression greatly deepens and extends the irony of the surface text, and narrows the distance between the narrator and the reader[1]. 


\subsection{Industrial Heritage Landscape}

The industrial heritage landscape is understood according to the definition of industrial heritage and related concepts of landscape. First, industrial heritage is an industrial heritage created by human activities. Second, industrial heritage includes material culture and intangible culture. It has multi-dimensional values, such as historical, economic, aesthetic, technological, and social values. Thirdly, landscape refers to the artificial or natural scenery of a place, including natural and artificial landscapes. Finally, combined with the concept of landscape, the industrial heritage landscape can be defined as an industrial area with industrial heritage characteristics and multi-dimensional value of industrial heritage and with landscape characteristics.

The value of industrial heritage is huge, and the industrial heritage landscape belongs to the category of industrial heritage, so the renewal and transformation of the industrial heritage landscape has considerable research value. In essence, the renewal and transformation of the industrial heritage landscape is actually the regeneration of the disabled space of the industrial heritage landscape and the multiple activation of various value dimensions through the relevant theories of landscape design. Including the identification of industrial heritage landscape elements in the early stage, the excavation of landscape history and culture, and the reorganization and redesign of landscape planning, in order to activate the vitality of industrial heritage, inherit and protect the historical and cultural connotation of industrial heritage landscape and other values, continue the vitality of industrial heritage landscape, and create an organic multiple life forms.

\subsection{Landscape Narrative}

Landscape narrative is a landscape design strategy extracted from the field of narratology and introduced into the field of landscape science, and translated into language symbols in landscape design through narratology-related theories, methods and language symbols to enhance the place spirit of the landscape and cultural identity. That is, after translating the symbols of narratology into symbols of landscape design, practitioners can design the landscape narratively according to the text of narratology. The text includes cultural texts, oral texts, historical texts, and story texts related to the site landscape, and uses related strategies in narratology to identify landscape elements, arrange spatial sequences, and create landscape artistic conceptions to enhance the landscape. The interactive relationship between the readability and the subject and object will ultimately enhance the meaning and aesthetic experience of the landscape place.

Another term for landscape narrative design is essentially the form of storytelling to preserve the historical memory of the site and convey the culture of the region. Therefore, the landscape exists as a carrier, and the narrative is used as a design strategy to empower the landscape to activate the site. Due to the differences between the subject and the object, the design narrator must learn to flexibly use various strategies and methods from narratology, and examine the internal relationship between text elements and landscape elements, and finally use appropriate methods to correct them. The translation and expression of landscape stories.

\section{The Inner Link Between Industrial Heritage Landscape and Landscape Narrative}

The industrial heritage landscape is the place where certain events and existing things take place, with unique regional characteristics, cultural characteristics, historical memory, and epochal characteristics. In the course of time, the development of social, economic, cultural, technological, aesthetic and other values has put forward new demands for industrial heritage landscapes. The national policy's emphasis on industrial heritage landscapes has given birth to the inheritance and protection of industrial heritage landscapes, leading the times. The transformation and reuse of industrial heritage landscapes have spawned new functional and innovative demands, the value of industrial aesthetics has spawned new aesthetic standards and technical demands, and the urgent need to improve spiritual culture has increased the cultural excavation and expression of industrial heritage landscapes.

Landscape narrative expression design is an expression design based on the landscape narrative discourse system. It is a landscape design structure system intertwined with times and stories. It is of the times and narrative. With the help of landscape narrative expression design, the industrial heritage landscape can be better expressed. Express spatial memory and preserve its unique historical memory. It is also used as a design thinking tool to help designers better explore the unique site characteristics of industrial heritage landscapes and the profound cultural connotations of industrial heritage landscapes, so as to improve the spiritual and cultural value of industrial heritage landscapes. And the unique plot and narrative of the landscape narrative expression design can be used as an artistic existence to demonstrate the vitality of the industrial heritage landscape. Finally, the unique discourse and structural order of the landscape narrative expression design can enhance the readability of the heritage landscape and the depth of the viewer's perception of the heritage landscape, so as to enhance the spiritual and cultural value of the industrial heritage landscape, and effectively shorten the distance between people and the landscape.

The research on the narrative expression design of industrial heritage landscape is currently only at the explicit level, that is, the research level of plot development, which belongs to the narrative expression of structuralism and lacks the exploration of text covert progression. Therefore, it is necessary to focus on covert progression Excavate and study the narrative expression of the industrial heritage landscape from the perspective of On the level, it supplements the skeleton of the narrative expression of the industrial heritage landscape, enriches the theoretical system, and serves as a set of feasible design principles and methods to guide the practice of the industrial heritage landscape. At the practical level, by digging deeply into the regional history and culture of the industrial heritage landscape, we can combine the plot development with the covert progression to construct a two-layer ideographic track in which the narrative expression of the industrial heritage landscape moves forward side by side, so as to inspire the viewers to have a better understanding of the site. The complex response highly restores the real historical memory and background of the industrial heritage in the era, enriches the narrative expression 
of the industrial heritage landscape, makes the overall character and expression of the industrial heritage landscape fuller and full of tension, and strengthens the viewer's understanding of the local landscape. Cultural experience of industrial heritage landscape and identification of spiritual and cultural values.

\section{The Strategy of Narrative Expression Design of Industrial Heritage Landscape under Covert Progression}

\subsection{Excavate the Significance of Landscape Covert Progression}

\subsubsection{Analyze the multi-dimensional value of the place}

Industrial civilization represents high speed and efficiency. Since the first industrial revolution, it has only been more than two hundred years since human beings entered the industrial society, creating huge wealth for the world and leaving a huge amount of industrial heritage for human society. The spiritual and cultural values contained in these industrial heritages are also solid and profound. It is true that the importance of the inheritance, protection and development of industrial heritage landscapes is extremely important, but at the same time, the problems faced by industrial heritage landscapes are also multi-dimensional and related to various value levels, including historical and cultural value, social value, and architectural aesthetic value., technological value, economic value, etc. Then, in the protection of industrial heritage, the relevant staff should not only carry out "divide and conquer" protection according to the type of site, but also at the design level, the reactivation and sustainable development of the disabled space of industrial heritage landscape, also need to engage in industrial heritage Relevant workers and designers of landscape protection and utilization pay attention from all levels of value, keep pace with the times, activate the lost industrial heritage landscape, and enhance and stimulate the vitality and value charm of the industrial heritage landscape. Therefore, in the design and research of the relevant staff, analyzing and excavating the value of each level of the site is the basis for the protection and reactivation of the industrial heritage landscape.

4.1.2 Excavate the significance of the theme of landscape covert progression

In the past, the thematic significance of excavating landscapes was almost always based on the exploration of the thematic significance of the narrative dynamics of the dominant process plot development, ignoring the exploration of the theme significance of covert progression. The covert progression and the explicit process are in a subversive or complementary relationship. If only the thematic significance of the explicit process is explored, it will have a negative impact on the ironic and deconstructed text elements and industrial heritage of the industrial heritage landscape itself. The thematic meaning of landscape works is seriously misunderstood. This kind of covert progression is hidden behind the explicit process, and has a complementary or subversive relationship with the explicit process in the sense of ethical value or theme, and generally has high aesthetic value. At the time, design researchers can use the research methods used to dig in-depth information about the historical, cultural, social, political, technological and other value dimensions of the place, and find out the ethical value or thematic meaning of the explicit process. The thematic significance of the subversive relationship enriches and complements the overall cultural and artistic connotation of the industrial heritage landscape. Moreover, the thematic meaning of covert progression often shows varying degrees of irony and deconstruction. Implanting its meaning into the site can make the final narrative expression of the industrial heritage landscape more full and tense.

\subsection{Constructing Landscape Covert Progression Text}

4.2.1 Design of text elements-theme, subject matter, semantics, artistic conception, carrier, subject

The design of narrative text includes theme, theme, semantics and artistic conception. After mining the value of the place and positioning the thematic meaning of the covert progression text, it is necessary to collect the text story themes related to the meaning of the covert progression to enrich the content and representation of the implicit narrative. The carrier, the source of the theme can be selected by mining historical fragments related to the theme of the site, community memory, family personal history, celebrity resumes, ritual activities or habitual behaviors, tourist stories, folklore, natural things evolution process and other information. Non-figurative story facts are distilled to complete the collection of covert progression text subject matter. The semantics of the narrative text includes the original meaning with surface semantic properties and the metaphorical meaning and extended meaning with deep semantic properties. It is attached to the element carrier of the text, and the narrative in the covert progression is carried out through the artistic conception formed by the logical relationship between the text element carriers. Semantic communication.

The design of the text carrier needs to have clear characteristics, such as the setting of the characteristics of the subject and object, historical background, political position, etc., which will make the theme clearer and improve the effectiveness of narrative expression. Later, the construction of landscape carrier elements often comes from textual information. The key information such as color, shape, and scene with clear and concrete features contained in the text is beneficial to provide clues for the narrative expression of landscape carrier elements. translate" into the vector form. The design of the text body of covert progression is based on the characters analysis and behavior design of the participants, community and stakeholders based on the text according to the relevant needs of the theme of covert progression. In classical narratology, the main body of the text pays more attention to the roles and functions of elites such as managers and designers. In postmodern narratology, more attention is paid to the discourse power of daily users, community residents, etc., that is, "me", rather than "others" such as foreign investors, developers, designers, etc. Dominate. Therefore, the text theme usually includes developers, operators, designers, users and tourists, as well as the design of the implied protagonist in the story. 
4.2.2 Organization of Text Elements-Ideographic Tracks Based on Covert Progression

After the elements of the text are established, it is necessary to construct the narrative expression elements of the covert progression based on the thematic meaning of the covert progression, which is to use the method of constructing the clues in the covert progression to deviated from the plot and show a different direction from the plot development. Text elements are arranged in the narrative text of the entire industrial heritage landscape, and non-figurative narrative techniques are implanted into it, so as to achieve the composition of narrative elements throughout the entire text of the industrial heritage landscape from beginning to end, thereby forming another line different from the obvious. The covert progression of the plot development of the sexual process, the narrative ideographic track and the narrative expression design text of the industrial heritage landscape under the covert progression, and to a large extent deepen and expand the irony of the surface text of the industrial heritage landscape, and increase the relationship between the text and the author., the distance between readers.

\subsection{Realize the Transformation of Textual Narrative Information}

4.3.1 Carrier selection and implantation based on implicit narrative text

After the landscape narrative text of covert progression is formed, it is necessary to transform the narrative text into the material and immaterial carrier text of the landscape. The material carrier text of the landscape includes buildings, flowers, trees, rocks, water bodies, garden roads, etc. Representational material texts; immaterial narrative media of landscapes, such as images, sounds, words and other non-representative immaterial texts. First of all, it is necessary to transform the relevant information of the text carrier elements of the covert progression narrative text, transform the landscape text into the landscape carrier text, and consider the adaptability of the visual expression of the industrial heritage landscape carrier text and the covert progression narrative text . Designers need to use the methods of analogy, refinement, generalization, connection, and imagination to visualize and visualize the abstract words in the landscape narrative text of the covert progression, and then provide elements and elements for the narrative expression of the landscape carrier in the covert progression. material. After the text is materialized, the materialized landscape carrier should be implanted according to the ideographic track formed by the text under the covert progression, so as to form the sequence and experience path of the industrial heritage landscape space under the covert progression, and realize the industrial heritage landscape. Narrative expression innovation under implicit power.

4.3.2 Rhetorical device empowers the carrier to realize the conveyance of semantic mood

Based on the successful materialization of the landscape sequence carrier of covert progression, designers need to further empower the landscape carrier to complete the conveyance of place semantics or artistic conception. Similes, metaphors, etc. are used to realize the materialization of the artistic conception of the landscape nodes and the conveyance of cultural semantics. The carrier empowerment under the covert progression allows viewers to see the complexity and multi-facetedness of the place in a deconstructive manner, often with varying degrees of irony, high aesthetic value, and enriching the industrial heritage landscape expression and the character tension of narrative expression.

4.3.3 Diversified activation under the value dimension to create sustainable life

The value dimension of industrial heritage landscape mainly includes historical and cultural value, social value, architectural aesthetic value, scientific and technological value and economic value. Among them, historical and cultural value is the most important. To protect historical value is to protect the historical and cultural features and authenticity of cultural heritage. In terms of time span, it is a witness to the history of urban industrial development, represents the achievements of civilization development preserved in the period of industrial civilization, is the epitome of urban industrial changes, and has strong regional cultural connotations. At present, in view of the lack of cultural connotation of the current industrial heritage, the regional cultural connotation can be deeply excavated through the narrative power under the covert progression, so as to effectively form the city's regional industrial heritage historical and cultural features. In terms of social value, on the one hand, designers should pay attention to the regeneration of the deactivated daily life space to meet the use value and exchange value of the space and prolong the life of the deactivated space, and on the other hand, to meet the emotional value of people in the city In terms of recognition, that is, the activation of historical and cultural value realizes the inheritance of the historical memory of industrial heritage and the spirit of the times, so that people have a more sense of belonging. In terms of architectural aesthetic value, industrial heritage buildings can reflect the architectural style and aesthetic level of the era, and have typical characteristics of the era. Designers protect and develop industrial historical buildings to coexist with modern buildings in the same space, increasing the architectural landscape. Diversity, avoiding the arbitrary sense of singleness, increasing the rarity and uniqueness of the urban landscape, and realizing the activation of the aesthetic value of the industrial heritage landscape. In terms of scientific and technological value, industrial heritage represents the level of production technology in the period. In the development process of industrial society, the level of industrial production technology determines the level of social and economic development. Including material production lines and production equipment and immaterial production technology, designers can integrate current technology while conveying regional history, technology and culture, making the site more dynamic and interesting. In terms of economic value, it can be linked with business to create landmark buildings, which will bring huge commercial value after being fully developed and utilized. From an economic point of view, products have four characteristics of "scarcity, purchasing power, demand and practicality". As a historical and cultural heritage, industrial heritage is a non-renewable resource, which determines the scarcity of historical and cultural blocks. To sum up, the 
industrial heritage landscape should be activated in a variety of value dimensions, so that the overall content of the industrial heritage landscape will be fuller, so as to create a sustainable life form of the industrial heritage landscape and realize the symbiosis of multiple values.

\section{The Illustration Concept Map of Landscape Narrative Expression Design}

\subsection{Excavate the Significance of Landscape Covert Progression}

\subsubsection{Analyze the multi-dimensional value of the place}

When analyzing the various value dimensions of the park, at the historical and cultural level, it is found that the excavation of the history and culture of the site is not comprehensive enough. The regeneration only pays attention to the glorious history of the park, but neglects the history of how the park once declined, and these are of warning significance. Therefore, the excavation of the culture of the park by the designers is lacking and incomplete, which will also lead to insufficient experience and understanding of the authenticity of the cultural connotation. Enhance the viewer's understanding of the multi-faceted and complex industrial heritage landscape, enrich the narrative expression of the industrial heritage landscape, at the level of social value, most of the inactive spaces are activated, and the functions are also reset with the times. Art galleries, museums, weekly international markets, the construction of commercial complexes, etc. are all meeting the material and spiritual needs of people in social values. The technological value can also be integrated into more new technologies to attract people. Inject more entrepreneurial opportunities and vitality into the park, and at the commercial level, more formats can be introduced to enrich the commercial value of the park.

5.1.2 Excavate the significance of the theme of landscape covert progression

When excavating the historical and cultural background, we capture the dominant landscape narrative of the Taoxichuan Park, that is, the thematic significance of the plot development is mainly based on "the past glorious history of the park, to continue and develop the vitality of the park", and understand that the Taoxichuan Park used to be Jingdezhen. One of the "Top Ten Porcelain Factories", which laid the foundation for modern ceramic production in Jingdezhen, but with the corporate restructuring in the 1990s, all the "Top Ten Porcelain Factories" "died" almost overnight, and the rest were just empty. Various types of ceramic workshops. However, the aspect of "the history of corporate decay to enrich the cultural connotation of the park", which has a complementary or subversive relationship with the explicit process in ethical value or thematic sense, has not been deeply explored. People review the reasons for the decline of the porcelain factory at that time, and look for deficiencies and experience from the decline, so as to remind contemporary entrepreneurs, governments and related personnel not to go back to the same way, so that viewers can have more aspects of the narrative expression of the industrial heritage landscape. With complex understanding, it has a certain deconstructionist nature.

\subsection{Constructing Landscape Covert Progression Text}

5.2.1 Design of text elements-theme, subject matter, semantics, artistic conception, carrier, subject

According to the value analysis of the place and the meaning of the theme of covert progression, "find the historical reasons for the decline of enterprises, alert contemporary enterprises and related personnel, and enrich the cultural connotation of the park", take the historical reasons for the decline of enterprises as the theme, and refine them. The semantics of the relevant reasons are extracted from the above, such as the semantics of one of the themes "Jingdezhen "Top Ten Porcelain Factory" only knows that it sticks to the title of "Millennium Porcelain Capital", and the porcelain that once made Jingdezhen proud is no longer as brilliant as it used to be. Taking a proud and conservative rather than open attitude in the development of an enterprise will make the enterprise decline step by step, so as to play a certain warning role, and attach it to the narrative text whose carrier is the text, so as to form a logical relationship between the elements of the text and text. The artistic conception is conveyed in the narrative semantics in the covert progression.

\subsubsection{Organization of Text Elements-Ideographic Tracks} Based on Covert Progression

Reshape the industrial period scene of the decay of the predecessor of Tao Xichuan, the Universe Ceramics Factory. According to the reasons for the decline, the themes of different reasons are used as the hidden narrative power. Multiple lines of parallel covert progression ideographic tracks, and non-figurative narrative skills are implanted into them. It forms an irony against the once prosperous porcelain capital of thousands of years, constitutes a tendency of deconstruction, enriches the viewer's more multi-faceted and complex understanding and experience of the park, and makes the overall character of the park fuller and the expression more intense.

\subsection{Realize the Transformation of Textual Narrative Information}

5.3.1 Carrier selection and implantation based on implicit narrative text

Based on the construction of the text of the ideographic track of the covert progression, the narrative text of the park's covert progression is completely transformed into the material and immaterial carrier text of the landscape, and the abstract sentences in the narrative text of the covert progression landscape are transformed into the artistic conception, and the use of analogy, refinement and generalization , connection, imagination and other techniques, transform abstract words into landscape carriers, and visualize and visualize them. For example, Jingdezhen's "Top Ten Porcelain Factory" only knows that it sticks to the title of "Millennium Porcelain Capital", which has been cited by Jingdezhen as a proud porcelain is no longer as brilliant as it used to be. "Transform this sentence of the text into a site construction of a landscape node, and select the carrier according to the elements required for construction, which can be translated into, with the help of a materialized art installation, to form an entrepreneur figure 
made of clay. The image is hunched and holding a pile of ceramics with the title of "Millennium Porcelain Capital". Another scenario that leads to success, and finally forms irony through this comparison, which has a high aesthetic value, thus forming the transformation of the narrative information of this sentence, and finally realizing the transformation of the narrative information of the entire text.

5.3.2 Rhetorical device empowers the carrier to realize the conveyance of semantic mood

After the industrial heritage landscape carrier text is materialized based on the covert progression text to form a sequence, a rhetorical device with a high degree of adaptation is selected to implant it into the corresponding non-figurative text to achieve the semantic transmission of the text. For example, "due to the poor management of enterprises, market, system, technological reform, management, government and many other reasons, a serious debt crisis can be caused" through a form of sculpture, using marble as the material, with a face struggling because of the huge burden of RMB "The sculptural image of the entrepreneur who is bent and walked with difficulty due to gravity, is a metaphor for the phenomenon of corporate debt, employee unemployment, and intensification of social contradictions caused by various reasons such as enterprises, government, market, and system, so as to realize the artistic conception of landscape nodes and places. Materialized construction and cultural semantic transmission. It allows viewers to see the complexity and multi-facetedness of the place, which enriches the expression of industrial heritage landscape and the character tension of narrative expression.

5.3.3 Diversified activation under the value dimension to create sustainable life

After objectively analyzing the value of the place, in terms of activating the historical and cultural value, designers can combine the park narrative expression design under the above covert progression with the park narrative expression design under the previous explicit process. Create a rich local historical and cultural connotation, protect the historical and cultural features and authenticity of cultural heritage, and at the technological level, when protecting and inheriting the past material and intangible culture, more new technologies can be integrated into the site to enable The park is more dynamic and attractive. At the commercial economic level, more business formats can be introduced to enhance the four characteristics of "scarcity, purchasing power, demand and practicability" of the overall products of the park, enrich the commercial value of the park, and make the overall content of the park landscape fuller, so as to create a park The landscape is sustainable life, and realizes the symbiosis of multiple values.

\section{Conclusion}

This paper draws on the theory of related disciplines of narratology, and based on the perspective of covert progression, constructs a narrative track of industrial heritage landscape narrative expression, form process and ideology, in order to stimulate viewers' more complex responses to the site, enrich the narrative expression of industrial heritage landscape, and make industrial heritage landscapes more complex. The overall character and expression of the heritage landscape are fuller and more intense, which strengthens the viewer's cultural experience and recognition of the spiritual and cultural values of the local industrial heritage landscape, and realizes the problems of the lack of cultural connotation and multi-dimensional values that the industrial heritage landscape faces. It not only enriches and deepens our understanding of the place-making, thematic meaning and aesthetic value of the narrative expression of industrial heritage landscape to a large extent, but also helps us to see the complexity and multi-facetedness of the overall industrial heritage landscape.

\section{Acknowledgement}

This paper is supported by the projects: General project of Jiangxi Provincial Social Science Planning: Research on landscape Activation Design of Industrial Heritage from the perspective of Landscape Narrative (No.: 21YS06); General Project of Social Science Planning of Jiangxi Province: Narrative Design of urban Red Landscape (No.: 20YS06); General project of cultural and art planning science in Jiangxi Province: Research on the construction method of urban red landscape from the perspective of narratology (No.: YG2020033); General project of Humanities and Social Sciences of Education Department of Jiangxi Province: Research on industrial Development System of Contemporary Inheritance of Chinese Painting Art (No.: YS20101).

\section{References}

[1] Shen Dan. The dual dynamics of narrative: Different interactions and reasons for neglect[J]. Journal of Peking University (Philosophy and Social Sciences Edition), 2018, 55(02): 84-97.

[2] Zhang Qian. The value charm of urban industrial heritage[J]. People's Forum, 2019(34): 74-75.

[3] Wang Yan, Wang Xinyu. Research on the "catalytic" renewal strategy of urban industrial heritage: Taking Changzhou Qiji Factory as an example[J]. Decoration, 2021(07): 132-133.

[4] Chen Huaxin, Meng Zhaojun, Zhang Xiaomei, Wang Jianqiu. Research on the reuse design of regional industrial heritage $[\mathrm{J}]$. Furniture and Interior Decoration, 2021(01): 93-95.

[5] Lu Shaoming. On the connotation, theory and value of landscape narrative $[\mathrm{J}]$. Journal of Nanjing University of the Arts (Art and Design), 2018(03): 59-67+209.

[6] Jiang Yina. The writing of cultural identity in the "space narrative" of Chinese contemporary landscape design[J]. Sichuan Opera, 2019(10): 53-56.

[7] Matthew Portage, Jamie Plington[America]; Zhang Nan, $\mathrm{Xu}$ Yuemeng, Tang Li, Li Nio translated, Landscape narrative: The design practice of storytelling[M], China Construction Industry Press, 2015

[8] Jiang Xiaoying. Research on narrative design of industrial heritage landscape[D]. Huazhong University of Science and Technology, 2019.

\section{Author Profile}

Hui Lin(1966.9-), male, Yushan, Jiangxi, China. Professor of 
College of Urban Construction, Jiangxi Normal University, research direction: interior decoration and landscape design.

Ke Xing(1998.6-), female, Nanyang, Henan, China. Master of Environmental Art, College of Fine Arts, Jiangxi Normal University.

Xiaogang Chen(1978.9-), male, Duchang, Jiangxi, China. Associate professor, master's supervisor, teacher of School of Urban Construction, Jiangxi Normal University, research direction: landscape architecture planning theory and design. 